\title{
Ultra high molecular weight polyethylene doped with iron through high energy mechanical alloying
}

\author{
José Flávio Marcelino Borges ${ }^{1}$, Michele Mugnaine ${ }^{1}$, Alexandre Camilo Junior ${ }^{1}$, \\ Fabiana Cristina Nascimento Borges ${ }^{1}$, Osvaldo Mitsuyuki Cintho ${ }^{2}$
}

\footnotetext{
${ }^{1}$ Department of Physics - State University of Ponta Grossa, Av. Carlos Cavalcanti 4748, CEP: 84030-900, Ponta Grossa, Paraná, PR, Brasil.

${ }^{2}$ Department of Materials Engineering - State University of Ponta Grossa, Av. Carlos Cavalcanti 4748, CEP: 84030-900, Ponta Grossa, Paraná, PR, Brasil.

e-mail: fborges@uepg.br, michelemug@hotmail.com,jr.acamilo@gmail.com, fabianacristinanascimento@gmail.com, omcintho@uepg.br, fborges@uepg.br.
}

\begin{abstract}
Doping polymers with metallic materials can improve significantly its use. Ultra high molecular weight polyethylene is known for its high resistance to abrasion and impact, and also for its friction coefficient, which is significantly lower than that of commercial steel and most polymeric materials. Therefore, this material presents high industrial demand despite its processing difficulty due to its high viscosity. One kind of polymer processing which has been widely used recently is the high energy mechanical alloying. This method provokes significant changes in the material, such as crystalline structure transformation, amorphization, formation of metastable phases, and nanostructuring, among others. In order to investigate the influence of iron dopant in structural characteristics of polymeric matrix, ultra high molecular weight polyethylene were doped with low concentrations (between 0.1 at.\% and 1 at.\%) of iron using the method of high energy mechanical alloying. The samples composition was characterized by X-Ray Diffraction Mössbauer Spectroscopy. A theoretical molecular modeling was carried out to simulate the iron presence in polymeric cell, which is in good agreement with the experimental results. Therefore, there is evidence that part of the iron promotes a crossed bond between the polymeric chains.
\end{abstract}

Keywords: Ultra high molecular weight polyethylene (UHMWPE), High energy mechanical alloying, Mössbauer Spectroscopy, structural properties.

\section{INTRODUCTION}

The structure of polyethylene is composed of crystalline and amorphous regions. In general, the polyethylene crystalline structure is orthorhombic at room temperature and low pressure [1,2]. Although the orthorhombic structure is more stable, the monoclinic structure can be mechanically induced. The ultra-high molecular weight polyethylene (UHMWPE) is a high density polyethylene, around $0.93-0.94 \mathrm{~g} / \mathrm{cm}^{3}$, white and opaque, with glass transition temperature around $-100{ }^{\circ} \mathrm{C}$ and $-125^{\circ} \mathrm{C}$ and fusion temperature $135^{\circ} \mathrm{C}$, with about $45 \%$ crystallinity [3]. The UHMWPE main characteristic is its high average molar mass which is about $4 \times 10^{6} \mathrm{~g} / \mathrm{mol}$, commercially varying between $3 \times 10^{6}$ and $8 \times 10^{6} \mathrm{~g} / \mathrm{mol}$ [4]. The material is almost totally inert, which makes it suitable to be used in almost all kinds of aggressive or corrosive environments at moderate temperatures [2]. This kind of polyethylene resists to higher abrasion and impact than most thermoplastics; its coefficient of friction is significantly lower than that of the commercial steel and most of the polymeric materials [4]. Its long molecular chain, high density and absence of ramifications in its structure result in other properties such as: high corrosion resistance, high cyclical wearing resistance, high noise absorption, high stress fracture resistance, high chemical resistance, high hardness, and excellent dielectric properties [2,3].

High energy mechanical alloying is a processing technique for powder in solid state with repeated processes of welding and breacking of powder particles, whose processing energy is higher than that of the conventional ball mills [5]. Throughout the milling, several parameters have some effect on the powder final result. These parameters are: kind of mill used; milling container; milling speed; milling time; milling power (ball mass/powder mass); amount filled in the container; milling atmosphere; and control of temperature [5]. 
It was believed that the high energy mechanical alloying could cause polymer degradation due to the continuous breacking of long chains, causing a number of resulting small chains without any useful physical property. However, it was verified that the polymer high energy mechanical alloying process can result in new bonds, when the chain is broken or there is hydrogen absence, forming free radicals that promote reactions between chains $[6,7]$. Other modifications can occur in this process as well, such as ramification of chains, change in molecular mass, formation of crossed bonds, net formation, surface and crystallinity. This method can also be used to incorporate additives and form polymeric alloys [8, 9]. In Smith et al. [10] it was seen that, due to the process that occurs during milling, there might be a break in the polymeric chain or hydrogen absence, making the chain reactive through the formation of free radicals, which might result in molecular mass reduction or a chemical reaction. Barbosa et al. [11] observed changes in the polyethylene crystalline phase from orthorhombic to monoclinic metastable. Olmos et. al. [12] observed that some flakes were formed after UHMWPE milling in a high energy mill and related this form to the monoclinic crystalline phase transformation.

Kaloshkin et. al. [13] reported UHMWPE synthesized by mechanical alloying with bronze and observed that samples have a better abrasive resistance and lower coefficient of friction. The focus of this study is the investigation of high energy mechanical alloying of ultra high molecular weight polyethylene doped with small concentrations of pure metallic iron powder. In this work the samples obtained were characterized through X-ray diffractometry, Mössbauer spectroscopy, and optical microscopy.

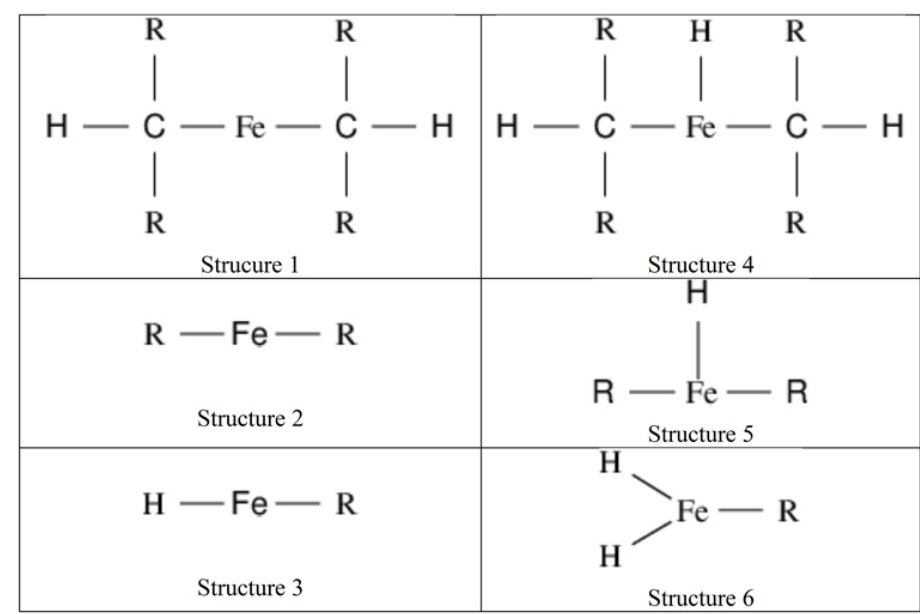

Figure 1: Models used to simulate crossed bonds between iron atoms and polyethylene chains. $\mathrm{R}=-[\mathrm{CH} 2] \mathrm{n}-\mathrm{CH} 3, \mathrm{n}: 0 \ldots 100$

In order to simulate the behavior of possible crossed bonds promoted by iron atoms between the polyethylene chains, six structures were proposed. These are representative of $\mathrm{Fe}^{2+}$ and $\mathrm{Fe}^{3+}$ configurations, as shown in Figure 1. The variation of stabilizing energies for these chains was studied as a function of the heavy atoms number present in the molecules, varying the number of carbon atoms up to approximately 100 , depending on the structure. In order to determine these molecules stabilization energy the semi-empirical method PM6 [14, 15] was implemented in the package MOPAC2012, Linux version [16]. Our results suggest higher stability of $\mathrm{Fe}^{2+}$-based structures. Inclusion of ferromagnetic particles in polymers is especially important as magnetic particles have shown promise in various potential applications like spinpolarized devices, carriers for drug delivery, magnetic recording media, conductive polymers, high-frequency applications, etc $[17-21]$.

\section{MATERIALS AND METHODS}

The samples were prepared using ultra high molecular weight polyethylene UTEC 6541, produced by Braskem, with average molar mass of $8 \times 10^{6} \mathrm{~g} / \mathrm{mol}$ and $130 \mu \mathrm{m}$ average particle size. The preparation process took place in two steps. The first one, samples were doped with $99.5 \%$ pure iron powder in master batch format, which was prepared through milling in a Spex mill (SPEX CertPrep model Mixer/Mill), mixing 0.25 volumetric fractions of iron powder for each fractions of polyethylene UTEC 6541, in an ambient atmosphere. The milling time was 3.5 hours and the milling power employed was 4.7:1 (21 g milling balls for $4.5 \mathrm{~g}$ sample). This first step was necessary to obtain homogeneity of the iron distribution in the final sample and avoid decanting of the metallic material, clearly heavier than the polymer. We used this master batch to obtained, in second step, samples were milled with different iron concentrations using an Attritor (Union Process, model 01-HD) mill. Four $40 \mathrm{~g}$ samples were prepared intentionally doped with $0.1,0.25,0.5$ and 1.0 at $\%$ of iron. Small concentrations of iron were chosen to avoid degradation in the structure of the polyethylene. The milling time was 8 hours for each sample, which is short enough to avoid significant variation in the sample processing temperature. All 
milling utensils used for the preparation of samples (container, shaft, and milling balls) were made of hardened steel, the atmosphere was not controlled during milling, the milling power employed was 50:1 (2000 g milling balls for $40 \mathrm{~g}$ sample), mill rotation was $300 \mathrm{rpm}$ and cooling throughout milling was made with current water. A reference sample was obtained using the same treatment process, without iron doping. This sample was called $0 \mathrm{wt} \%$ iron. For the X-ray diffractometry (XRD) and Mössbauer spectroscopy, the samples were pressed into a sheet format using the hydraulic press with two hot shape. Pressing was carried out with a load of approximately 3 tons, for 3 minutes at $200{ }^{\circ} \mathrm{C}$.

XRD analyses were carried out at the UEPG Multiuser Laboratory, employing a Shimadzu XRD-6000 diffractometer with copper Ka radiation with $1.5418 \mathrm{~nm}$ line width. The Mössbauer spectroscopy was carried out in transmission geometry, at room temperature, without magnetic field. The UHMWPE samples without milling and the ones processed in mills were characterized in an optical microscope Olympus model BX51. Bright field reflected light was employed.

In order to study the stability of possible crossed bonds between iron atoms and polyethylene chains, a theoretical study on the electronic and geometrical properties of polyethylene oligomers containing iron atoms in different positions in the chain was carried out. The stabilization energy of structures shown in Figure 1 were simulated, keeping the iron atom position fixed in relation to the polyethylene and varying the number of carbon atoms up to approximately 100 atoms. The starting structures were built employing the Molden program [22]. The molecular system modeling can be carried out through a variety of theoretical methods, with different degrees of accuracy and computational effort necessary to determine the stabilization structures. The semi-empirical PM6 method was chosen in order to determine the heat of formation and respective oligomer geometries for being the first semi-empirical method to present parameterization for the $\mathrm{Fe}$ atom. Another reason for that choice is that, from a theoretical point of view, the long oligomer size presents high computational cost for the use of ab-initio methods or DFT, but presents good cost/benefit relation regarding semi-empirical methods. The heat of formation/number of heavy atoms ratio was analyzed as a function of the inverse of the number of heavy atoms in the chain. These values were used to make the linear regression, and thus, the heat of formation per heavy atom in chains with the iron proportion obtained experimentally could be estimated.
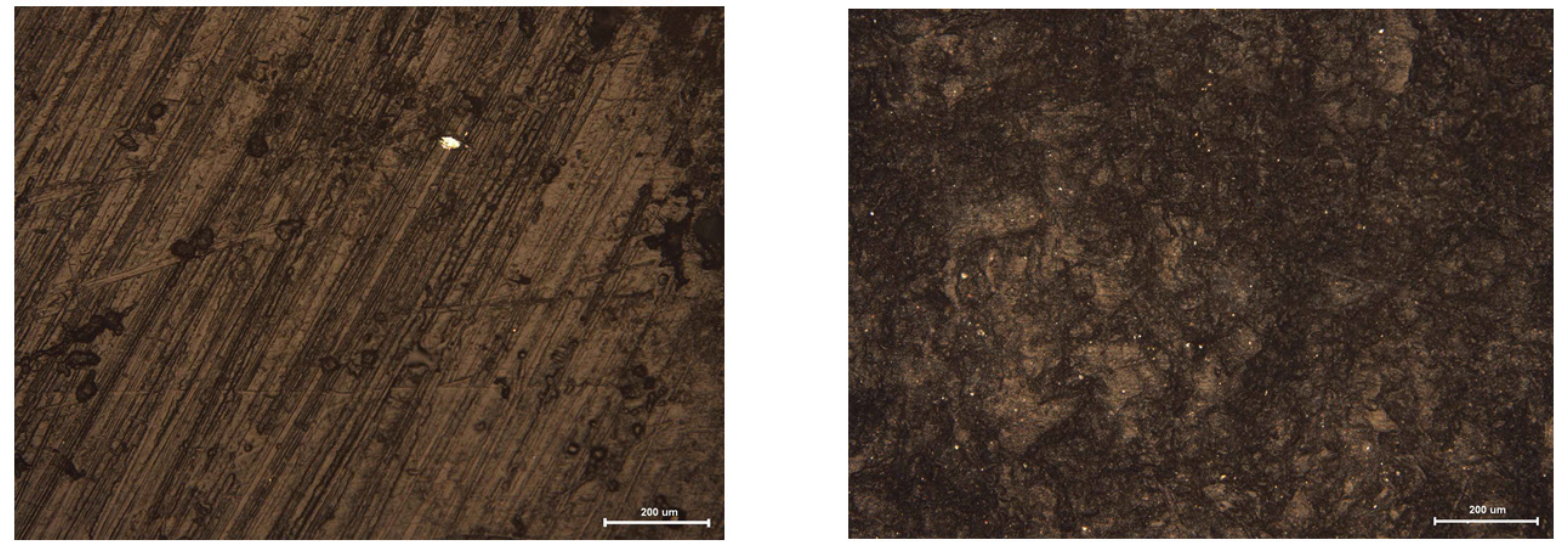

Figure 2: Microscopy in the UTEC polymer bright field free of doping (A), with enlargement factor 100x, and the 1.0at $\%$ iron doped polymer (B) enlargement factor 100x

\section{RESULTS AND DISCUSSIONS}

Figure 2 presents the optical microscopy images of UHMWPE samples without and with 1.0 at\% Fe doping. Particles observed in Figure 2A of the iron free sample ( 0 at $\% \mathrm{Fe})$ have come from the milling container, due to the high abrasion coefficient of the polyethylene, as it was found out in previous studies [23]. Particles, in contrast to the dark background, coming from the contaminant metal are medium-large sized (approximately $24 \mu \mathrm{m}$ ) when compared to the powder used in the polymer doping as it can be seen in the image of the sample 1.0 at $\% \mathrm{Fe}$ (Figure 2B). It is also possible to see that the amount of contaminant is significantly smaller reaching $1.33 \times 10^{-5}$ particles/ $\mu \mathrm{m}^{2}$ in the $1.0 \mathrm{at} \% \mathrm{Fe}$ doped sample. Wilson et. al. [20] reported that few particles on the surface confirming that the particles tend to migrate below the surface. The $\mathrm{XRD}$ results (Figure 3) present peaks related to the polyethylene. Such peaks are identified as regarding the aluminum and a small peak corresponding to the metallic iron, only visible in the diffractograms of 0.5 at $\%$ and $1 \mathrm{at} \% \mathrm{Fe}$ samples at about the $45^{\circ}$ angle, overlapping an aluminum peak. 


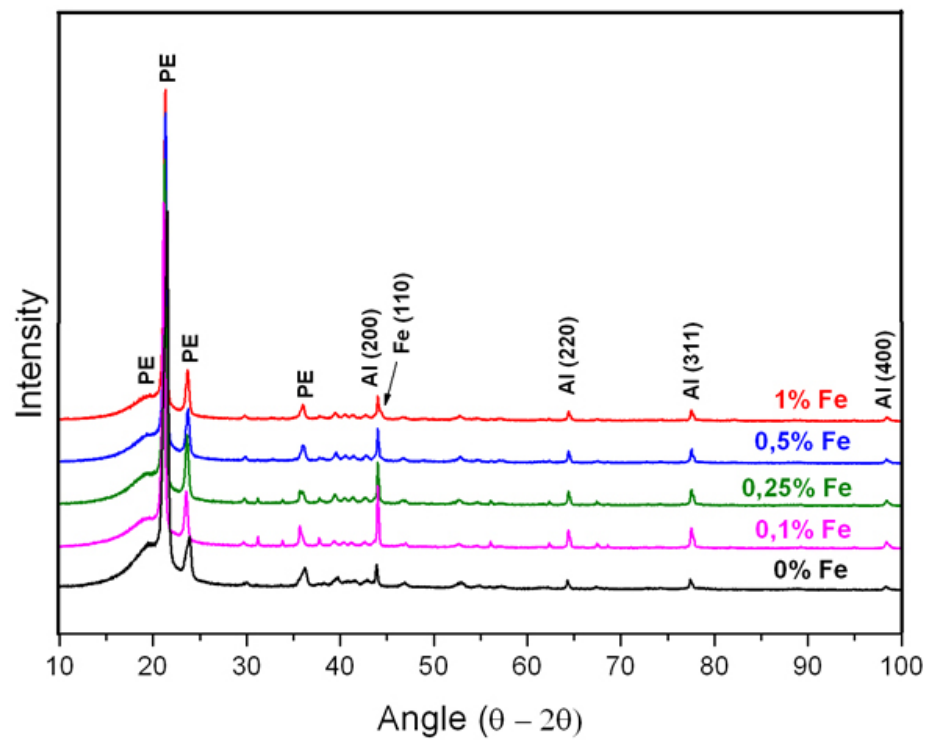

Figure 3: Pure polyethylene sample and iron doped sample X-ray diffractograms
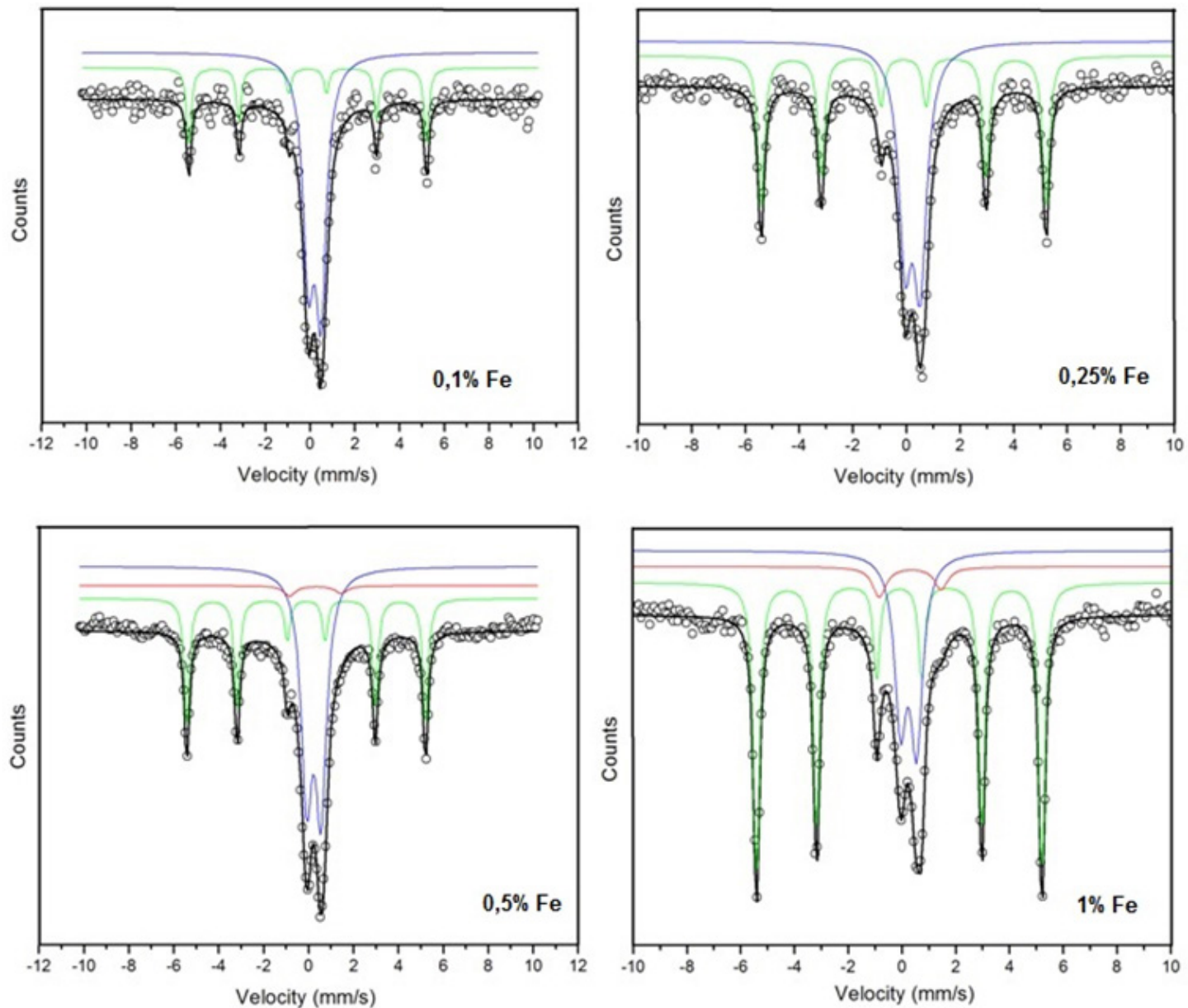

Figure 4: The Mössbauer spectroscopy of polyethylene with different iron doping. The sextet sub-spectrum are related to the metallic iron. The highest intensity central doublets are related to the iron paramagnetic particles. Smaller doublets that appear in the figures underneath are related to the $\mathrm{Fe}^{2+}$.

The polyethylene peaks, at about $2 \theta=21^{\circ}, 2 \theta=24^{\circ}$ and $2 \theta=36^{\circ}$ correspond to the orthorhombic phase according to ICPDS (International Center for Diffraction Data) data $\mathrm{n}^{\circ} 11-0834$. The XRD analyses did not reveal changes for the monoclinic phase mechanically induced through the incorporation of metallic iron into the polymeric matrix in monoclinic 
phase. Peaks regarding aluminum do not come from the sample; they originate from the aluminum used to make the equipment sample support, in which the diffractometry was carried out, and they appear due to the thickness of the sample and the polymer translucency.

Table 1: Iron doped samples Mössbauer adjusted data

\begin{tabular}{|c|c|c|c|c|c|c|}
\hline DOPING & SITES & $\begin{array}{c}\text { BHF } \\
(\mathrm{kOe})\end{array}$ & $\begin{array}{c}\Gamma \\
(\mathrm{mm} / \mathrm{s})\end{array}$ & $\begin{array}{c}\text { IS } \\
(\mathrm{mm} / \mathrm{s})\end{array}$ & $\begin{array}{c}\Delta \mathrm{Eq} \\
(\mathrm{mm} / \mathrm{s})\end{array}$ & $\begin{array}{c}\text { AREA } \\
(\%)\end{array}$ \\
\hline 0 at $\% \mathrm{Fe}$ & A & 0 & 0.5 & 0.22 & 0.31 & 100 \\
\hline \multirow{2}{*}{0.1 at $\% \mathrm{Fe}$} & $\mathrm{A}$ & 0 & 0.59 & 0.2 & 0.28 & 60.4 \\
\hline & B & 330 & 0.25 & -0.11 & 0 & 39.6 \\
\hline \multirow{2}{*}{0.25 at $\% \mathrm{Fe}$} & $\mathrm{A}$ & 0 & 0.59 & 0.23 & 0.28 & 41.9 \\
\hline & B & 330 & 0.29 & -0.11 & 0 & 58.1 \\
\hline \multirow{3}{*}{0.5 at\% $\mathrm{Fe}$} & $\mathrm{A}$ & 0 & 0.6 & 0.23 & 0.32 & 46.4 \\
\hline & $\mathrm{B}$ & 330 & 0.28 & -0.11 & 0 & 52.0 \\
\hline & $\mathrm{C}$ & 0 & 0.6 & 0.3 & 1.15 & 1.6 \\
\hline \multirow{3}{*}{$1.0 \mathrm{at} \% \mathrm{Fe}$} & $\mathrm{A}$ & 0 & 0.54 & 0.24 & 0.3 & 23.2 \\
\hline & $\mathrm{B}$ & 330 & 0.27 & -0.11 & 0 & 74.0 \\
\hline & $\mathrm{C}$ & 0 & 0.6 & 0.3 & 1.15 & 2.8 \\
\hline
\end{tabular}

The 0 at $\%$ Fe sample Mössbauer spectroscopy revealed the presence of paramagnetic iron coming from the contamination of the milling vial as reported by Borges et. al. [23] This iron was interpreted as small contaminating particles inserted interstitially in the polymer matrix. In 0.1 at $\%$ and 0.25 at $\%$ Fe samples, metallic iron was identified besides the presence of paramagnetic iron in the central doublet. In 0.5 and 1.0 at $\%$ Fe samples, a third phase was observed, clearly identified as $\mathrm{Fe}^{2+}$, double ionized iron particles, which increased with the amount of metal added. This particle might be entering between the polymeric chains promoting crossed bonds, as pointed out by Smith and his team, [10] which results in interesting changes to the ground material properties. Mössbauer Spectroscopy of $0.1 \mathrm{at} \%, 0.25$ at $\%, 0.5$ at $\%$ and 1.0 at $\% \mathrm{Fe}$ samples can be seen in Figure 4, in which each sextet sub-spectrum presents the clear signature of pure metallic iron, with a $330 \mathrm{kOe}$ hyperfine field. The highest intensity central doublets are related to the iron paramagnetic particles. Smaller doublets that appear in the figures underneath are related to the $\mathrm{Fe}^{2+}$ mentioned above.

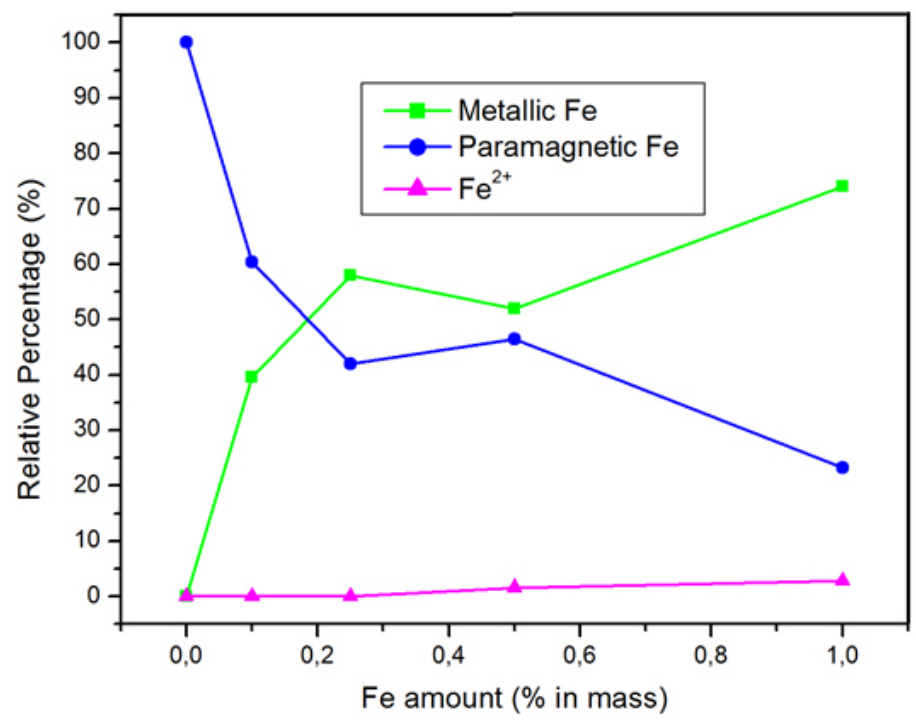

Figure 5: Percentage regarding iron phases found in the polymers as a function of the dopant element concentration.

In Table 1, values used to adjust each of the sub-spectrum found in the samples measured can be seen, and in Figure 5 it is possible to see clearly the evolution of the iron phases found in the polymeric samples as a function of the variation in the metallic element amount. 


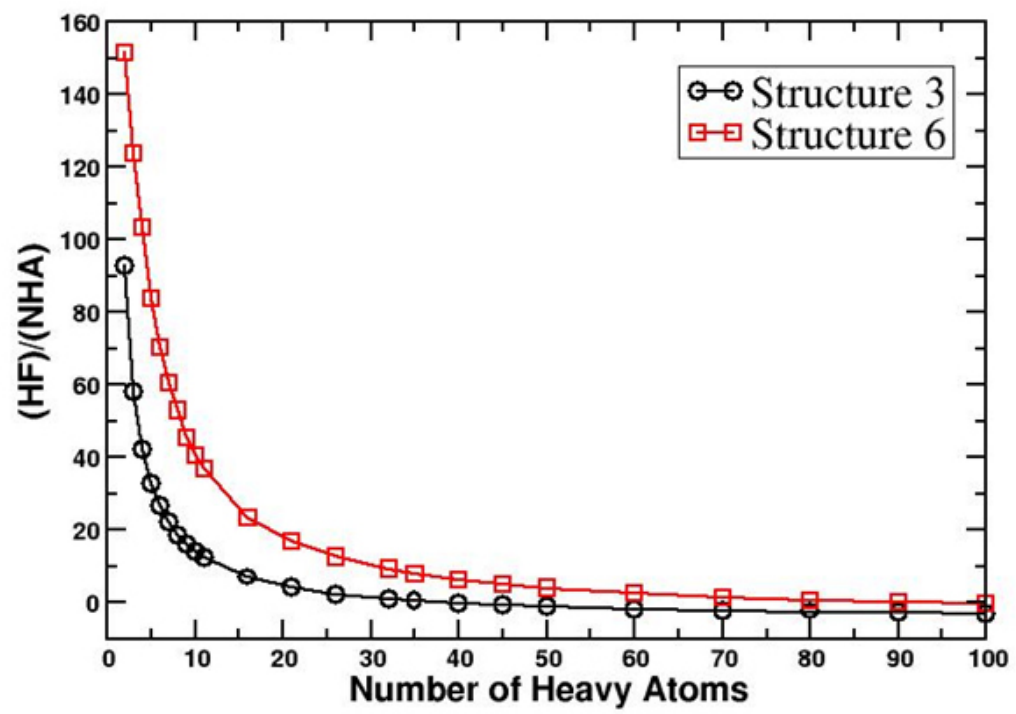

Figure 6: Evolution of the Heat of Formation/Number of Heavy Atoms ratio against the Number of Heavy Atoms in the oligomer

From the point of view of the molecular modeling, the first analysis carried out to determine whether the molecules geometry were converging with the oligomer increase was the determination of the molecule heat of formation distribution in relation to the number of heavy atoms that enter its composition. The main goal is to determine whether the method chosen, the Hamiltonian semi-empirical PM6, describes the structures shown in Figure 1 in a realistic way. In Figure 6, results are presented for structures 3 and 6; similar behavior is observed for the remaining structures proposed. They were grouped in order to compare the $\mathrm{Fe}^{2+}$ and $\mathrm{Fe}^{3+}$ structures with the same number of heavy atoms and the same position of $\mathrm{Fe}$ atom bonds with the polymeric chain. As it can be seen, there is a fast convergence of Heat of Formation /Number of Heavy Atoms (HF/NHA) ratio against the number of heavy atoms in all cases. This behavior indicates that the PM6 gives a good description of such structures. These graphs also show that the $\mathrm{Fe}^{2+}$-based structures present lower stabilization energy than those based on $\mathrm{Fe}^{3+}$, that is, this model predicts higher probability of the $\mathrm{Fe}^{2+}$ forming stable bonds with the polymer chains.

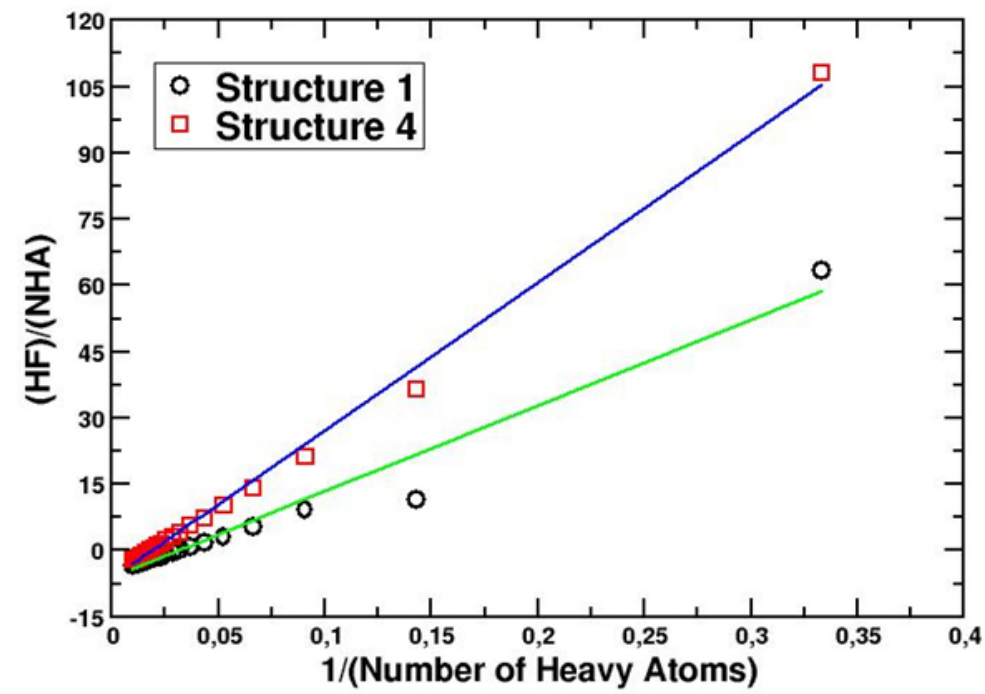

Figure 7: Evolution of the Heat of Formation/Number of Heavy Atoms ratio against the inverse of the Number of Heavy Atoms in the oligomer; straights represent linear regression

In this study, molecules of about 100 heavy atoms were investigated, simulating structures of at least 4.5 at $\% \mathrm{Fe}$ in mass, in relation to the total number of heavy atoms and approximately 3.8 at $\%$ in relation to the molecule total mass. Samples with 0.1 to 1.0 at $\% \mathrm{Fe}$ were obtained experimentally. In order to obtain such proportion, molecules of about 470 heavy atoms would have to be built to simulate $0.1 \mathrm{at} \%$, which suggests a good field for further investigation. 
In order to evaluate the energy distribution per heavy atom in the proportion of experimental samples and determine which species were the most stable, the HF/NHA ratio against the inverse of heavy atoms number was analyzed. It is represented in Figure 7 for the structures 1 and 4. The straight lines represent the linear regression for the molecule complete sets of structures that represent the $\mathrm{Fe}^{2+}$ compounds (Structure 1) and $\mathrm{Fe}^{3+}$ (Structure 4). These are for structure 1,

$$
\mathrm{y}=-4.9149+153.22 \mathrm{x}
$$

and for structure 2

$y=-5.2686+291.19 x$.

In these equations, $y$ is the HF/NHA ratio and $x$ is the inverse of the Number of Heavy Atoms. Table 2 presents some stabilization energy values, obtained with this equation in concentrations of iron in mass for the heavy atoms existing in the molecule. As it could be seen, with low iron concentration, the $\mathrm{Fe}^{3+}$ species presents lower stabilization energy. For values above $1.0 \mathrm{at} \%$, the $\mathrm{Fe}^{2+}$ species presents lower stabilization energy, and it is more likely to be found. It is important to point out that these simulations were carried out for a molecule isolated in vacuum within the semi-empirical Hartree-Fock model, and they are in good agreement with the results obtained experimentally, which determined $\mathrm{Fe}^{2+}$ in the samples with 0.5 at $\%$ and 1.0 at $\%$ concentrations. Similar behavior is observed for the remaining structures proposed. In the theoretical study, we sought to work with oligomers representative of the proportion of Fe determined experimentally, but these corresponded to a small number of molecules. We chose to expand the calculations for oligomers that had a higher amount of Fe to observe, via extrapolation, what could when the amount of Carbon is reduced in relation to that of $\mathrm{Fe}$.

Table 2: Stabilization energy per heavy atom $(\mathrm{kcal} / \mathrm{mol})$, as a function of the iron concentration

\begin{tabular}{c|c|c}
\hline IRON DOPING (\%) & $\mathbf{F e}^{+\mathbf{2}}$ & $\mathbf{F e}^{\mathbf{+ 3}}$ \\
\hline $\mathbf{0 . 1 0}$ & $-6,111$ & -6.401 \\
\hline $\mathbf{0 . 2 5}$ & -6.049 & -6.293 \\
\hline $\mathbf{0 . 5 0}$ & -5.943 & -6.111 \\
\hline $\mathbf{1 . 0 0}$ & -5.734 & -5.751 \\
\hline $\mathbf{1 . 1 0}$ & -5.693 & -5.678 \\
\hline $\mathbf{2 . 0 0}$ & -5.310 & -5.019 \\
\hline $\mathbf{4 . 0 0}$ & -4.438 & -3.514 \\
\hline
\end{tabular}

\section{CONCLUSIONS}

It was seen that high energy mechanical alloying can be an excellent technique for solid state reaction to insert metals between ultra high weight polymeric chains.

The presence of $\mathrm{Fe}^{2+}$ in the Mossbauer spectroscopy results indicates the existence of a highly reactive particle which might be entering between polymeric layers and promoting the chain crossed bonds.

The iron doped polymer oligomers simulation for the structures proposed shows that the $\mathrm{Fe}^{3+}$ species presents lower stabilization energy in very low concentrations, while in concentrations higher than 1.0 at $\%$, $\mathrm{Fe}^{2+}$ is the dominating species, which is in accordance with results obtained experimentally. Also our results suggest higher stability of $\mathrm{Fe}^{2+}-$ based structures.

\section{ACKNOWLEDGMENTS}

Authors are thankful to UEPG/CLABMU, DF/UFSCar and to the financial support of Fundação Araucária.

\section{BIBLIOGRAPH}

[1] CORISH, P. J. Concise Encyclopedia of Polymer Processing \& Applications, Oxford, Pergamon, 1992.

[2] I. I. Rubin, Handbook of plastic materials and technology, New York, John Wiley \& Sons, 1990.

[3] COUTINHO, F.M.B., MELLO, I.L., SANTA MARIA, L.C. de, "Polietileno: principais tipos, propriedades e aplicações", Polímeros: Ciência e Tecnologia, v. 13, n. 1, pp. 1-13, 2003.

[4] Engineered Materials Handbook, V. 2, Engineering Plastics, ASM International, nov. 1988. 
[5] SURYANARAYANA, C., "Mechanical Alloying and Milling”, Progress in Materials Science, v. 46, pp. 1-184, 2001.

[6] SHAW, W. J. D., "Current Understanding of Mechanically Alloyed Polymers”, Materials Science Forum, v. 262-272, pp. 19-30, 1998.

[7] SMITH, A. P., SPONTAK, R. J. BALIK, C. M., et al. "High- energy mechanical milling of poly(methyl methacrylate), polyisoprene and poly(ethylene-alt- propylene)”, Polymer, v. 41, pp. 6271-6283, 2000.

[8] FONT, J., MUNTASELL, J., CESARI, E., "Effect of milling on the thermal behavior of poly(ethylene terephthalate)", Thermochimica Acta, v. 333, pp. 169-172, 1999.

[9] FONT, J., MUNTASELL, J., "Effect of ball milling on semicrystalline bisphenol A polycarbonate", Materials Research Bulletin, v. 35, pp. 681-687, 2000.

[10] SMITH, A. P., SPONTAK, R. J., ADE, H., et al. "High-energy cryogenic blending and compatibilizing of immiscible polymers", Advanced Materials, v. 11, n. 15, pp. 1277-1281, 1999.

[11] BARbosa, A. P. C., STRAnZ, M., KATZENBERG, F., et al. "Cryogenic mechanical milling of high density polyethylene", E-polymers, V. 96, p. 1146, 2009.

[12] OLMOS, D., DOMÍNGUEZ, P. D., CASTRILlO, P. D., et al. "Crystallization and final morphology of HDPE: Effect of the high energy ball milling and the presence of TiO2 nanoparticles”, Polymer, v. 50, pp. 1732-1742, 2009.

[13] KALOSHKIN, S. D., VANDI, L. J., TCHERDYNTSEV, V. V., et al. "Multi-scaled polymer-based composite materials synthesizedby mechanical alloying”, Journal Alloys and Compounds, v. 483, pp. 195-199, 2009.

[14] STEWART, J. J. P., “Optimization of Parameters for Semiempirical Methods V: Modification of NDDO Approximations and Application to 70 Elements”, Journal of Moecular Modeling, v. 13, pp. 1173-1213, 2007.

[15] ANDRADE, A. M., JUNIOR, A. C., LÁZARO, S. R., "Theoretical investigation on PEDOT polymeric chain structure through dimeric rotational barrier”, Current Physical Chemistry, v. 5, pp.301 - 307, 2015.

[16] STEWART, J. J. P., MOPAC2012 Computational Chemistry, HTTP://OpenMOPAC.net, USA, Colorado Springs, 2012.

[17] SUN, S., ANDRES, S., HAMANN, H. F., et al. "Polymer mediated self-assembly of magnetic nanoparticles", Journal of American Chemical Society, v. 124, pp. 2884-2885 2002.

[18] CHATTERJEE, J., HAIK, Y., CHEN, C. -J., "Polyethylene magnetic nanoparticle: a new magnetic material for biomedical applications", Journal of Magnetism and Magnetic Material, v. 246, pp. 382-291, 2002.

[19] ANDRADE, A. M., INACIO, P. L., JUNIOR, A. C., "Theoretical investigation of second hyper polarizability of transpolyacetylene: comparison between experimental and theorical results for small oligomers", Journal of Chemical Physics, v. 143, PP 244906_1-244906_7, 2015.

[20] WILSON, J. L., PODDAR, P., FREY, N. A., et al. "Synthesis and magnetic properties of polymer nanocomposites with embedded iron nanoparticles", Journal Applied Physics, v. 95, n. 3, pp. 1439-1443, 2004.

[21] KORCHAGIN, V. I., PROTASOV, A. V. STUDENIKINA, L. N. et al. "Prediction of processing parameters of secondary polyethylene with iron carboxylates in the preparation of prooxidants' additives" Vestnik Voronežskogo Gosudarstvennogo Universiteta Inženernyh Tehnologij, v. 79, pp. 232-236, 2017.

[22] SCHAFTENAAR, G. and NOORDIK J.H., "Molden: a pre and post-processing program for molecular and electronic structures" Journal Computer-Aided Molecular Design, v. 14, pp. 123-134, 2000.

[23] BORGES, J. F M, HNEDA, M. L., CINTHO, O. M., et al. "Mossbauer analysis of ultra-high molecular weight polyethylene subject to different milling times", Publicatio UEPG - Ciências Exatas e da Terra, Ciências Agrárias e Engenharias, v. 17, pp. 93-97, 2011.

\section{ORCID}

José Flávio Marcelino Borges

Michele Mugnaine

Alexandre Camilo Junior

Osvaldo Mitsuyuki Cintho

Fabiana Cristina Nascimento Borges https://orcid.org/0000-0002-1677-3118 https://orcid.org/0000-0002-8169-4723

https://orcid.org/0000-0003-3930-694X https://orcid.org/0000-0001-8567-5653

in memorian. 